\title{
International Welfare Spillovers of National Pension Schemes
}

By

James Staveley-O.Carroll_and Olena Staveley-O'Carroll

July 2019

COLLEGE OF THE HOLY CROSS, DEPARTMENT OF ECONOMICS

FACULTY RESEARCH SERIES, PAPER NO. 18-13*

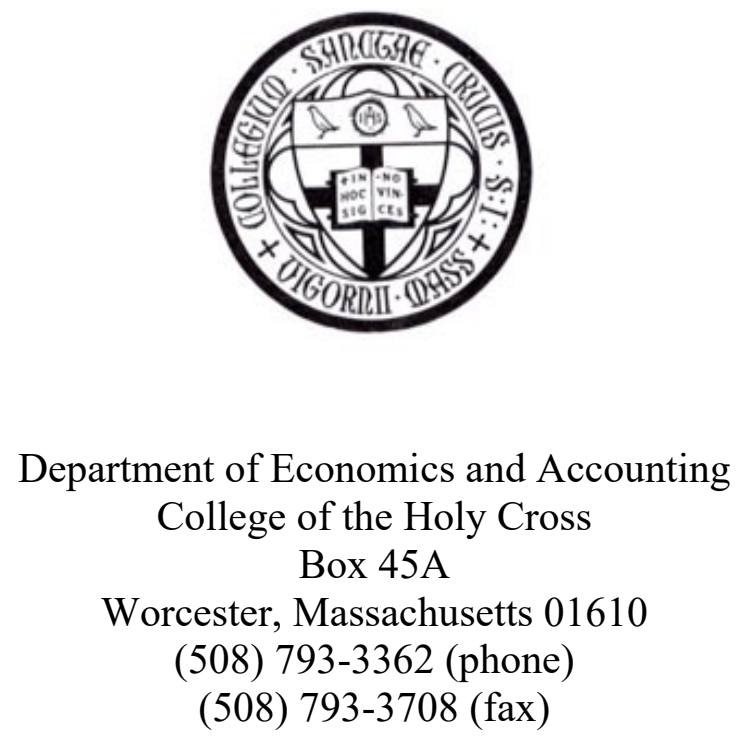

https://www.holycross.edu/academics/programs/economics-and-accounting

*All papers in the Holy Cross Working Paper Series should be considered draft versions subject to future revision. Comments and suggestions are welcome. 


\title{
International Welfare Spillovers of National Pension Schemes
}

\author{
James Staveley-O'Carroll* Olena M. Staveley-O'Carroll ${ }^{\dagger}$ \\ Babson College College of the Holy Cross
}

June 24, 2019

\begin{abstract}
We employ a two-country overlapping-generations model to explore the international dimension of household portfolio choices induced by the asymmetric provision of government-run pensions. We study the resulting patterns of risk-sharing and the corresponding welfare effects on both home and foreign agents. Introducing the defined benefits payas-you-go system at home increases the welfare of all other agents at the expense of the home workers and improves the degree of intergenerational risk sharing abroad. Conversely, a defined contributions system leads to welfare losses of both home cohorts accompanied by gains abroad, but does increase the extent of intergenerational risk sharing at home.
\end{abstract}

Keywords: welfare, pay-as-you-go system, international portfolio choice, OLG model JEL Classification: D52, F21, F41, G11, H55

Acknowledgement: We would like to thank conference participants at the 2018 Infiniti Conference on International Finance, Southern Economic Association 2018 Annual Meeting, and the 14th Annual Conference of Macroeconomists from Liberal Arts Colleges for valuable comments and suggestions. All remaining mistakes are our own.

* Corresponding author. Economics Division, Westgate Hall, Babson College, 231 Forest Street, Babson Park, MA 02457. Email: jstaveleyocarroll1@babson.edu

$\dagger$ Department of Economics and Accounting, Box 45A, College of the Holy Cross, One College Street, Worcester, MA 01610. Email: omykhayl@holycross.edu 


\section{Introduction}

As Shiller (1999) forcefully argues, risk sharing is the key objective of a staterun retirement system. While such a system may serve to mitigate saving myopia on the part of some individuals or to redistribute wealth within a society, its primary function is to protect the elderly from poverty via risksharing contracts that cannot be provided by private markets. In theory, a retiree can share her idiosyncratic risks with three groups of people: local young (intergenerational risk-sharing), local elderly (intragenerational), and foreign agents (international). In practice, the former group may be too young (or not even yet born) to be able to legally participate in such insurance schemes, creating room for a government-run pension system that can transfer risk across multiple generations. Most of the literature on the structure and welfare effects of such pension systems focuses on the interactions between different cohorts within a country. However, the rapid pace of globalization during the last four decades created a multitude of opportunities for crossborder risk-sharing and therefore all but ensured that national policies have important international spillovers that must not be ignored when designing and evaluating government programs such as the provision of pensions.

In a recent paper, Staveley-O'Carroll and Staveley-O'Carroll (2017) document and analyze the impact of asymmetries in the structure of national pension systems on international financial capital allocation. The authors show that specific features of a country's pension system influence its workers' consumption-saving decisions and have a direct impact on the composition of their international investment portfolios. ${ }^{1}$ An immediate follow-up question, taken up in this paper, is to quantify the welfare effects of these portfolio reallocations on both home and foreign agents and to study the resulting patterns of intergenerational and international risk-sharing induced by the introduction

\footnotetext{
${ }^{1}$ Dicks-Mireaux and King (1983), Hubbard (1985), and Ligon (1995) report statistically significant effects of social security wealth on household portfolio decisions, although no study explicitly includes foreign financial assets. Using reduced-form closed economy life cycle models, Hubbard et al. (1995) and Hubener et al. (2016) study how the presence of a social insurance program can influence household wealth accumulation (the former study) and portfolio choices (the latter paper).
} 
of a pension system in the home economy. As more and more governments contemplate reforms of their national pension systems made ever less sustainable by the global demographic shifts, it is important to understand (even if not explicitly take into account) the resulting cross-border financial readjustments that can in turn affect the extent of international business cycle propagation.

To the best of our knowledge, ours is the first paper to rigorously study international welfare effects of national social security systems, although a case for such a study was outlined in Shiller (1999). As such, our results augment the existing research that has so far focused on the within-country measures of welfare. One of the key results from the existing literature in this area shows that a pay-as-you-go (PAYG) social security system is welfare-reducing due to its crowding-out effect on national savings, capital accumulation, and growth (Diamond, 1965; Samuelson, 1975; Bruce and Turnovsky, 2013; Harenberg and Ludwig, 2015). On the other hand, social security can provide missing intraand/or intergenerational insurance opportunities against aggregate and idiosyncratic shocks when financial markets are incomplete (Bohn, 1999; Shiller, 1999; Storesletten et al., 1999; Krueger and Kubler, 2006; Sánchez-Marcos and Sánchez-Martín, 2006; Harenberg and Ludwig, 2015), which under certain circumstances can outweigh the growth-dampening effect of the program. In a study with a focus similar to ours, Beetsma et al. (2011) show that institutional design and investment strategies of a government-run fully funded pension fund in a two-pillar pension system can affect both intergenerational and international risk sharing in a fully symmetric two-period model. Complementing and extending the existing work in this field, we set aside the capital accumulation considerations and use the overlapping generations (OLG) framework to study jointly the national and international risk-sharing, capital allocation, and welfare consequences of private investment decisions induced by the existence of a PAYG pension system in one of the two countries.

Ours is a two-country, two-cohort OLG model in which both countries function as endowment economies with differentiated home and foreign goods. To properly capture the risk-sharing aspects of the economy, we carefully differentiate between risk aversion and intertemporal elasticity of substitution 
by employing Epstein-Zin preferences. Financial markets, in which agents can trade internationally in debt and equity assets, are incomplete for two reasons. First, cohorts cannot exchange risk with each other since shocks are realized only after the young workers are born. Second, human capital is assumed to be nontradable, so that the retirees cannot purchase claims on the wages of workers. In their first period of life, consumers in each country earn wages and invest a portion of their earnings into an array of financial assets. We assume that the home country maintains a PAYG retirement system, whereas the consumers in the foreign economy have to make their own retirement savings arrangements. More specifically, the home government imposes a tax on current workers and immediately distributes the proceeds to retirees. In the second (and last) period, retirees consume the payouts of their investments as well as the pension payments. Risk sharing is imperfect: local wage (dividend) shocks affect primarily the local young (retirees), although the young workers structure their portfolios in a way that does allow for some pooling of risks across different agent groups.

To obtain our welfare results, we first simulate the model without the pension system in either economy and record the resulting baseline expected welfare levels of the four agents (home and foreign, young and old). We then repeat the simulations having added a defined benefit (DB) PAYG system to the home economy and calculate the compensating variations - the percent changes in current consumption - required to make each of the four agents indifferent to the introduction of the social security system. We find that adding the DB PAYG pension framework in the home economy increases the average welfare of all other agents in the model at the expense of the home workers. At this point, it is important to clarify our language: the terms "added" or "introduced" refer to the differences between distinct modeling frameworks - with or without social security - rather than to transitional dynamics (that is, the explicit shift within the same model from having no pension system to starting it at a particular point in time). As such, our welfare comparisons of the different pension structures should be interpreted as pertaining to economies that have fully completed their transitions to a particular state-run pension 
framework. ${ }^{2}$

To better understand these results, we must consider the impact of the social security system, which, in essence, is a nontradable financial asset designed by the government, on the extent of risk sharing that agents can achieve using private financial markets. The young home cohort's loss, widely documented in the literature, stems from the loss of potential earnings in financial markets to the pension tax, since the PAYG system offers a zero real rate of return (in the absence of population growth). The gains to foreigners - a key contribution of this study - deserve further attention. The DB structure of the home retirement system reduces the overall riskiness of the home consumers' lifetime wealth by supplementing their stochastic future income with a risk-free second-period pension payment. In response, the home workers increase their holdings of (risky) home and foreign equity, financing them by borrowing from abroad. The resulting portfolio reallocation allows home workers to share the risk reduction induced by the PAYG system with the foreign consumers: the latter can offload some of their risky assets in exchange for (relatively safer) bonds. In fact, while doing little to improve risk sharing elsewhere in the model, the DB PAYG system increases the degree of intergenerational risk sharing in the foreign economy.

A different pattern of welfare spillovers emerges when we replace the DB system with a defined contribution (DC) structure. Both home cohorts experience welfare losses accompanied by gains abroad. Home workers no longer gain the increase in the security of their future income that characterizes the DB system, since the retirees get a portion of the stochastic wage income of the workers instead of a risk-free lump-sum payment. A corresponding drop in the equity investments of the young cohort translates into lower consumption (and so welfare) in retirement. Foreigners must now hold most of their portfolio risk rather than selling it to the home workers, but are rewarded with the corresponding higher average returns. As opposed to the DB structure, the

\footnotetext{
${ }^{2} \mathrm{~A}$ related - and extensive - strand of literature has undertaken the study of the transition period per se and of its implied welfare effects on different groups of economic agents. For reviews of the existing papers, see Feldstein and Liebman (2002), Diamond (2004), and Aubuchon et al. (2011).
} 
DC system leads to much higher risk sharing within generations and internationally. Home young and old are now sharing wage risk more equally, and this risk can also be hedged internationally via appropriately chosen portfolios of the home and foreign workers. This argument echoes the findings in Shiller (1999) and Krueger and Kubler (2006): with imperfectly correlated capital and labor returns, a PAYG social security system enables agents to pool the two sources of income and thereby improves on the limited risk-sharing opportunities offered by incomplete private financial markets.

Due to computational complexity of solving our model globally, we abstract from several important mechanisms that affect the functioning of pension systems, such as population growth, tax elasticity of labor supply, intra-cohort heterogeneity, and uncertainty regarding the duration of retirement. While undoubtedly essential for a complete understanding of the impact of such systems on the macroeconomy, these limitations allow us to provide a sharp focus on the relatively unexplored question of international welfare effects of asymmetric pension provisions. At the same time, our modeling assumptions imply that the main emphasis of our work is on the direction of the cross-border welfare spillovers rather than on their absolute magnitude. Our findings should be viewed as supplementing other welfare gains and losses associated with social security systems that have been documented elsewhere in the literature.

The organization of the paper is as follows. We present the theoretical model and our calibration strategy in Section 2. The third section describes consumer portfolio choice and the resulting patterns of risk sharing in the baseline model, and the changes induced in these variables by the introduction of the DB and DC social security systems. Section 4 explores the international welfare outcomes of these portfolio allocation decisions and thereby of the asymmetric provisions of national pension schemes, with several robustness checks reported in Section 5. Finally, we summarize our findings and list several future extensions of our work in Section 6 . 


\section{Model}

The model, taken directly from Staveley-O'Carroll and Staveley-O'Carroll (2017), features two countries with overlapping-generations consumers who receive stochastic imperfectly correlated wage and dividend income and can trade bond and equity assets across national borders. The two economies differ only in the pension system provision. In the home country, the government administers a pure PAYG social security system, in which each period a portion of the workers' stochastic earnings are transferred to the retirees. In the foreign economy, workers must rely solely on private financial markets to save for retirement. In this section, the indicator $i=\{h, f\}$ denotes equations that hold for both the home and foreign cohorts.

As a matter of notation, superscripts are used to denote agent-specific variables (country of residence and period of birth), whereas subscripts will refer to economy-wide indicators such as country of production and the time period. Below, we outline the most salient features of the model and the solution methodology and refer the interested reader to the original paper for details.

\subsection{Production}

Both countries have endowment economies. Perishable output of each country is comprised of wages and dividends,

$$
y_{i, t}=w_{i, t}+d_{i, t}
$$

each of which is in turn determined exogenously by a two-state Markov process. Thus, home wages $w_{h, t}$ can be either low, $W_{h, 1}$, or high, $W_{h, 2}$, and evolve according to the following symmetric transition matrix:

$$
P\left(w_{h, t}=W_{h, 1} \mid w_{h, t-1}=W_{h, 1}\right)=P\left(w_{h, t}=W_{h, 2} \mid w_{h, t-1}=W_{h, 2}\right)=\lambda_{w, h} .
$$


Home dividends, foreign wages, and foreign dividends follow analogous processes with parameters $\left\{D_{h, 1}, D_{h, 2}, \lambda_{d, h}\right\},\left\{W_{f, 1}, W_{f, 2}, \lambda_{w, f}\right\}$, and $\left\{D_{f, 1}, D_{f, 2}, \lambda_{d, f}\right\}$, respectively.

The home and foreign outputs are combined into consumption bundles, available to the young and old cohorts in the home and foreign countries, according to constant elasticity of substitution (CES) aggregator

$$
\begin{aligned}
c_{t}^{h, j} & \equiv\left[\phi_{h, t}^{1-\sigma}\left(c_{h, t}^{h, j}\right)^{\sigma}+\left(1-\phi_{h, t}\right)^{1-\sigma}\left(c_{f, t}^{h, j}\right)^{\sigma}\right]^{\frac{1}{\sigma}} \text { for } j=\{t, t-1\} \\
c_{t}^{f, j} & \equiv\left[\phi_{f, t}^{1-\sigma}\left(c_{f, t}^{f, j}\right)^{\sigma}+\left(1-\phi_{f, t}\right)^{1-\sigma}\left(c_{h, t}^{f, j}\right)^{\sigma}\right]^{\frac{1}{\sigma}} \text { for } j=\{t, t-1\}
\end{aligned}
$$

where $\sigma$ measures the elasticity of substitution between imports and exports. The time-varying parameter $\phi_{i, t}$ captures the extent of home bias in consumption $^{3}$

$$
\phi_{i, t} \equiv \phi_{i}+e_{t}
$$

where $e_{t}$ is an i.i.d. process with $e_{t} \in\{-e, e\}$.

The exogenous state of the economy can be defined as $z_{t}=\left\{e_{t}, w_{h, t}, w_{f, t}, d_{h, t}, d_{f, t}\right\}$, which follows a first-order Markov process with finitely many states, $\mathcal{Z}=$ $\left\{z_{1}, \ldots, z_{32}\right\}$.

Given the prices $P_{h, t}$ and $P_{f, t}$ of the home and foreign output measured in local currency and assuming that the Law of One Price holds, we can calculate the CPIs as

$$
\begin{aligned}
& P_{t}^{h}=\left[\phi_{h, t}\left(P_{h, t}\right)^{\frac{\sigma}{\sigma-1}}+\left(1-\phi_{h, t}\right)\left(S_{t} P_{f, t}\right)^{\frac{\sigma}{\sigma-1}}\right]^{\frac{\sigma-1}{\sigma}} \\
& P_{t}^{f}=\left[\phi_{f, t}\left(P_{f, t}\right)^{\frac{\sigma}{\sigma-1}}+\left(1-\phi_{f, t}\right)\left(\frac{P_{h, t}}{S_{t}}\right)^{\frac{\sigma}{\sigma-1}}\right]^{\frac{\sigma-1}{\sigma}},
\end{aligned}
$$

\footnotetext{
${ }^{3}$ Judd, Kubler, and Schmedders (2003) show that in a standard Lucas tree model with time-separable preferences, complete asset markets, and no financial frictions, agents' portfolios are typically constant over time and states of nature; consequently, capital flows are absent in equilibrium. Since we want the portfolio choices of the households to evolve endogenously from any starting value in response to pension system asymmetries, we must move away from the assumption of complete markets. Having more shocks (five in our model) than assets (four) is a sufficient condition for asset market incompleteness.
} 
where $S_{t}$ is the nominal exchange rate, expressed in units of home currency per one unit of foreign currency. In the rest of the paper, we deflate all prices by the local CPI and refer to these real variables using lower-case letters. Additionally, we define the real exchange rate (RER) as $q_{t} \equiv \frac{S_{t} P_{t}^{f}}{P_{t}^{t}}$.

\subsection{Consumers}

Agents are representative within each cohort and optimize their behavior over their working years and retirement. By assuming zero population growth, we maintain equal sizes of the two cohorts, normalized to unity, in all periods. The young cohort earns wages, pays social security taxes, and saves a portion of its disposable income for retirement. The old cohort consumes all of its savings, dividend income, and pension benefits.

Workers born in period $t$ derive utility from current consumption and their future value function using Epstein-Zin (EZ) preferences, while retired workers only receive utility from their last period consumption:

$$
\begin{aligned}
v_{t}^{i, t} & \equiv\left\{\left(c_{t}^{i, t}\right)^{1-\gamma}+\beta E\left[\left(v_{t+1}^{i, t}\right)^{1-\alpha}\right]^{\frac{1-\gamma}{1-\alpha}}\right\}^{\frac{1}{1-\gamma}} \\
v_{t+1}^{i, t} & \equiv c_{t+1}^{i, t}
\end{aligned}
$$

where $\beta$ discounts future consumption, $\alpha$ controls relative risk aversion, and $\gamma$ represents the inverse of the elasticity of intertemporal substitution (EIS). This particular form of the utility function is important for analyzing policies that can simultaneously affect both the level and the riskiness of a consumer's period-by-period income stream. Note that when $\alpha=\gamma$, the preferences are equivalent to those under constant relative risk aversion (CRRA).

The workers maximize utility (5) by investing a portion of their disposable wage income into the four available assets. Since the old cohort liquidates all of their asset positions, the following notation pertains to the asset holdings of the young cohort. Each unit of stock $a_{i, t}$ with the corresponding price $q_{i, t}$ entitles its holder to the future dividend stream $d_{i, \tau}$ where $\tau \in\{t+1, t+2, \ldots\}$. Bonds $b_{i, t}$, measured in the units of home and foreign consumption bundles, 
respectively, offer real rates of return next period equal to $1+r_{i, t} \cdot{ }^{4}$ Each country has one unit of stock and both bonds are in zero net supply. Young households choose their period- $t$ consumption $c_{t}^{i, t}$ and the allocations $a_{h, t}^{i, t}, a_{f, t}^{i, t}$, $b_{h, t}^{i, t}$, and $b_{f, t}^{i, t}$ subject to the following budget constraints:

$$
\begin{aligned}
c_{t}^{h, t}+b_{h, t}^{h, t}+q_{t} b_{f, t}^{h, t}+q_{h, t} a_{h, t}^{h, t}+q_{t} q_{f, t} a_{f, t}^{h, t} & =\Omega_{t}^{h, t}-\kappa I_{t}^{h} \\
c_{t}^{f, t}+\frac{1}{q_{t}} b_{h, t}^{f, t}+b_{f, t}^{f, t}+\frac{1}{q_{t}} q_{h, t} a_{h, t}^{f, t}+q_{f, t} a_{f, t}^{f, t} & =\Omega_{t}^{f, t}-\kappa I_{t}^{f}
\end{aligned}
$$

Old households simply consume their entire wealth

$$
c_{t+1}^{i, t}=\Omega_{t+1}^{i, t}+\kappa I_{t+1}^{i} .
$$

A transfer payment $\kappa$ is made whenever the older cohort enters the period with zero wealth; therefore, if $\Omega_{t+1}^{i, t}=0$, then $I_{t+1}^{i}=1$, otherwise $I_{t+1}^{i}=0$.

The period- $t$ wealth $\Omega_{t}^{i, t}$ of the representative worker is equal to her disposable wage earnings:

$$
\Omega_{t}^{i, t} \equiv p_{i, t}\left[\left(1-\tau_{i}\right) w_{i, t}-T_{i}\right]
$$

The government can collect social security contributions from the workers in two ways: as a lump-sum tax $T_{i}$ or as a fraction $\tau_{i}<1$ of the wage. This allows us to model both a defined benefits PAYG system with $T_{i}$ and a defined contributions system with $\tau_{i}$. Each household's second period wealth $\Omega_{t+1}^{i, t}$ is the sum of the social security transfers and the payouts of the period- $t$

\footnotetext{
${ }^{4}$ An interesting and related - albeit highly theoretical - question concerns the potential of wage- or GDP-indexed assets in increasing intergenerational risk sharing. We do not pursue it here since such instruments do not yet exist in private financial markets, although we refer the interested reader to arguments in, for example, Fischer (1983), Shiller (1999), and Beetsma et al. (2011).
} 
investments:

$$
\begin{aligned}
\Omega_{t+1}^{h, t} \equiv & p_{h, t+1}\left(\tau_{h} w_{h, t+1}+T_{h}\right)+\left(1+r_{h, t}\right) b_{h, t}^{h, t}+q_{t+1}\left(1+r_{f, t}\right) b_{f, t}^{h, t}+ \\
& \left(q_{h, t+1}+p_{h, t+1} d_{h, t+1}\right) a_{h, t}^{h, t}+q_{t+1}\left(q_{f, t+1}+p_{f, t+1} d_{f, t+1}\right) a_{f, t}^{h, t} \\
\Omega_{t+1}^{f, t} \equiv & p_{f, t+1}\left(\tau_{f} w_{f, t+1}+T_{f}\right)+\frac{1}{q_{t+1}}\left(1+r_{h, t}\right) b_{h, t}^{f, t}+\left(1+r_{f, t}\right) b_{f, t}^{f, t}+ \\
& \frac{1}{q_{t+1}}\left(q_{h, t+1}+p_{h, t+1} d_{h, t+1}\right) a_{h, t}^{f, t}+\left(q_{f, t+1}+p_{f, t+1} d_{f, t+1}\right) a_{f, t}^{f, t}
\end{aligned}
$$

Consumers can short any asset; however, to guarantee the compactness of the model state space, we require that their next period wealth $\Omega_{t+1}^{i, t}$ be non-negative:

$$
\min \Omega_{t+1}^{i, t} \geq 0
$$

Equation (13) can be interpreted as a borrowing constraint on domestic bond holdings $b_{i, t}^{i, t}$ :

$$
\begin{aligned}
b_{h, t}^{h, t} \geq & \frac{1}{1+r_{h, t}} \min \left\{p_{h, t+1}\left(\tau_{h} w_{h, t+1}+T_{h}\right)+q_{t+1}\left(1+r_{f, t}\right) b_{f, t}^{h, t}+\right. \\
b_{f, t}^{f, t} \geq & \left.\frac{1}{1+r_{f, t}} \min \left\{p_{h, t+1}+p_{h, t+1} d_{h, t+1}\right) a_{h, t}^{h, t}+q_{t+1}\left(q_{f, t+1}+p_{f, t+1} d_{f, t+1}\right) a_{f, t}^{h, t}\right\} \\
\left.\frac{1}{q_{t+1}}\left(q_{h, t+1}+p_{h, t+1} d_{h, t+1}\right) a_{h, t}^{f, t}+\left(q_{f, t+1}+p_{f, t+1} d_{f, t+1}\right) a_{f, t}^{f, t}\right\} & (15)
\end{aligned}
$$

\subsection{Closing and solving the model}

The state of nature of the model economy in period $t$ is given by the beginningof-period wealth distribution of the two cohorts of retirees, $\Omega_{t}^{h, t-1}$ and $\Omega_{t}^{f, t-1}$, the five exogenous shocks $z_{t}=\left\{e_{t}, w_{h, t}, w_{f, t}, d_{h, t}, d_{f, t}\right\}$, and tax policies $T=$ $\left\{T_{h}, T_{f}, \tau_{h}, \tau_{f}, \kappa\right\}$. A competitive equilibrium is a price system $P_{t} \equiv\left\{q_{t}, p_{h, t}, p_{f, t}, q_{h, t}, q_{f, t}, r_{r, t}, r_{f, t}\right\}$, an allocation of goods $C_{t} \equiv\left\{c_{t}^{h, t}, c_{t}^{h, t-1}, c_{t}^{f, t}, c_{t}^{f, t-1}\right\}$, and asset positions $A_{t} \equiv$ $\left\{a_{h, t}^{h, t}, a_{h, t}^{f, t}, a_{f, t}^{h, t}, a_{f, t}^{f, t}, b_{h, t}^{h, t}, b_{h, t}^{f, t}, b_{f, t}^{h, t}, b_{f, t}^{f, t}\right\}$ such that

1. given the price system, the allocation and asset positions solve the home and foreign consumers' utility maximization problems, and 
2. goods and financial markets clear:

$$
\begin{aligned}
c_{i, t}^{h, t}+c_{i, t}^{h, t-1}+c_{i, t}^{f, t}+c_{i, t}^{f, t-1} & =y_{i, t} \\
a_{i, t}^{h, t}+a_{i, t}^{f, t} & =1 \\
b_{i, t}^{h, t}+b_{i, t}^{f, t} & =0
\end{aligned}
$$

for $i=\{h, f\}$.

The model is solved globally over a compact state-space grid following the methodology outlined in Stepanchuk and Tsyrennikov (2015). As detailed in Staveley-O'Carroll and Staveley-O'Carroll (2017), in order to minimize computational time, we reduce the number of endogenous state variables to one through a series of variable re-definitions. The two retired cohorts' wealth levels are combined into an aggregate $\Omega_{t}^{t-1}$ :

$\Omega_{t}^{t-1} \equiv p_{h, t}\left(\tau_{h} w_{h, t}+T_{h}\right)+p_{f, t}\left(\tau_{f} w_{f, t}+T_{f}\right)+\left(q_{h, t}+p_{h, t} d_{h, t}\right)+q_{t}\left(q_{f, t}+p_{f, t} d_{f, t}\right)$

This allows us to determine the distribution of wealth between the retired cohorts:

$$
\omega_{t}^{h, t-1} \equiv \frac{\Omega_{t}^{h, t-1}}{\Omega_{t}^{t-1}}
$$

The borrowing constraint (13) guarantees the compactness of the state space and restricts the wealth ratio $\omega_{t}^{h, t-1}$ to lie within the $[0,1]$ interval. The wealth ratio is sufficient to describe the endogenous state variables in the model. The control variables $P_{t}, A_{t}$, and $C_{t}$ and the transition equation for the wealth ratio can be expressed as functions of the exogenous state $z_{t}$, tax policies $T$, and the one endogenous state variable $\omega_{t}^{h, t-1}$.

We rely on numerical simulations of the model to uncover the channels that link the national choice of the pension system to the resulting welfare of the home and foreign consumers in both cohorts. We next describe the calibration choices used in these simulations. 


\subsection{Calibration}

The benchmark specification is described in Table 1; unless otherwise indicated, all parameters describing the foreign economy are identical to the ones in the home country.

Each period in the model represents 25 years; thus, we assume that each worker starts his life and career at the age of 25 , retires at the age of 50 , and lives until the age of 75 . We set the intertemporal discount factor $\beta=0.375$; given the $4 \%$ annual real rate of return $(r)$ commonly assumed in the business cycle literature and the 25-year duration of each period in our model $(T)$, the parameter $\beta$ solves $(1+r)^{T}=\beta^{-1}$.

The EZ preference parameters $\alpha$ and $\gamma$, which control the degree of risk aversion and the EIS, govern consumer portfolio choices and are therefore crucial for understanding the patterns of international capital movements. Unfortunately, there is no consensus in the literature on the empirical estimates of these parameters. We do not wish to take a stance on a particular set of values for $\gamma$ and $\alpha$; rather, we want to elucidate the impact of consumer risk and time preferences on the resulting investment decisions. To this end, in the baseline calibration we follow the (average) findings of van Binsbergen et al. (2012) and set $\gamma=0.5$ and $\alpha=60$, and later perform several robustness checks to study these parameters' impact on our findings.

We assume that home and foreign goods are imperfect substitutes in consumption, $\sigma=1 / 3$, and let the average home bias parameters be $\phi_{h}=\phi_{f}=$ $0.75 .^{5}$ The degree of trade openness changes by $5 \%$ relative to the average, so that $\left\{e_{1}, e_{2}\right\}=\{-0.05,0.05\}$.

We use the moments of the annual series for U.S. compensation of employees and capital income (expressed in real per capita terms and HP-filtered) to calibrate the processes for model wages and dividends. To this end, we set $\lambda_{h, w}=0.522$ and $\lambda_{h, d}=0.513$, equivalent to the annual wage and dividend autocorrelations of 0.62 and 0.47 , respectively. We normalize the av-

\footnotetext{
${ }^{5}$ Notice that, given the CES aggregators (1) and (2), the elasticity of substitution between home and foreign goods is equal to $\frac{1}{1-\sigma}$.
} 
Table 1: Benchmark parameter values

\begin{tabular}{lll}
\hline \hline Parameter & Description & Value \\
\hline$\beta$ & Intertemporal discount factor & 0.375 \\
$\alpha$ & Relative risk aversion coefficient & 60 \\
$\gamma$ & Inverse of elasticity of intertemporal substitution & 0.5 \\
$\phi_{h}, \phi_{f}$ & Average consumption home bias & 0.75 \\
$\sigma$ & Import/export elasticity of substitution & $1 / 3$ \\
$W_{i, 1}, W_{i, 2}$ & Wage realizations for $i \in\{h, f\}$ & $0.745,1.255$ \\
$D_{i, 1}, D_{i, 2}$ & Dividend realizations for $i \in\{h, f\}$ & $0.257,0.592$ \\
$\lambda_{i, w}$ & Persistence in the wage process for $i \in\{h, f\}$ & 0.522 \\
$\lambda_{i, d}$ & Persistence in the dividend process for $i \in\{h, f\}$ & 0.513 \\
$T_{h}$ & Pension tax, lump sum (with $\left.\tau_{h}=0\right)$ & $\{0.10,0.28,0.47\}$ \\
$\tau_{h}$ & Pension tax, distortionary (with $\left.T_{h}=0\right)$ & $\{0.124,0.362,0.599\}$ \\
\hline \hline
\end{tabular}

erage wage and dividend in each country to 1 and 0.42 to match the share of capital to labor income in the U.S. Based on this normalization, we set $\left\{W_{h, 1} ; W_{h, 2}\right\}=\{0.745 ; 1.255\}$ and $\left\{D_{h, 1} ; D_{h, 2}\right\}=\{0.257 ; 0.592\}$ to produce the volatilities observed in the data. ${ }^{6}$

We consider two different versions of the model: DB, with the lump-sum pension tax $T_{h}>0$ (and $\tau_{h}=0$ ), and DC with only a distortionary tax $\tau_{h}>0$ (and $\left.T_{h}=0\right)$. The calibration of the pension taxes and benefits, taken directly from Staveley-O'Carroll and Staveley-O'Carroll (2017), is somewhat convoluted by the assumption that there is an equal number of workers and retirees in our model. If we match the level of the tax burden on the workers, we significantly underestimate the resulting benefits per retiree. On the other hand, matching the pension benefits requires setting the level of tax far above that observed in the data. To compromise, we simulate the model using three different tax values listed in the last two rows of Table 1: low (matching the empirical tax burden), high (matching the retirement benefits), and middle (the average of the first two).

\footnotetext{
${ }^{6}$ See Staveley-O'Carroll and Staveley-O'Carroll (2017) for a detailed explanation of the calibration strategy and for data sources and descriptions.
} 


\section{Distribution of aggregate risks}

In a closed economy setting, a social planner who cares equally about all generations redistributes the aggregate output $w_{h, t}+d_{h, t}$ to equalize the marginal utilities of consumption of both cohorts (see, for example, Bohn, 2009). Given the utility functions (5) and (6), this requirement simplifies to $c_{t}^{h, t}=c_{t}^{h, t-1}$, implying perfect intergenerational risk sharing. Extending this finding to a two-country setting, a global social planner who can capture and reallocate the output across borders would additionally ensure that the marginal utilities of consumption, scaled by the RER, equalize between the two countries:

$$
\frac{\partial v_{t}^{h, t} / \partial c_{t}^{h, t}}{\partial v_{t}^{f, t} / \partial c_{t}^{f, t}}=q_{t}
$$

a familiar condition in two-country settings with complete asset markets (Chari, Kehoe, and McGrattan, 2002). As such, relative consumptions and the RER should be perfectly correlated.

\subsection{Benchmark social planner problem}

A social planner who cares equally about all agents maximizes the combined utility of all agents in the model constrained only by the goods clearing conditions (16) given the exogenous shock processes $z_{t}$. Using Lagrangian multipliers, $\lambda_{h, t}$ and $\lambda_{f, t}$, the social planner's intratemporal problem can be written as follows:

$$
\begin{aligned}
& \max v_{t}^{h, t}+v_{t}^{h, t-1}+v_{t}^{f, t}+v_{t}^{f, t-1} \\
& +\lambda_{h, t}\left(y_{h, t}-c_{h, t}^{h, t}-c_{h, t}^{h, t-1}-c_{h, t}^{f, t}-c_{h, t}^{f, t-1}\right) \\
& +\lambda_{f, t}\left(y_{f, t}-c_{f, t}^{h, t}-c_{f, t}^{h, t-1}-c_{f, t}^{f, t}-c_{f, t}^{f, t-1}\right) .
\end{aligned}
$$

We plug the definition of the consumption bundles (1) and (2) into the utility functions (5) and (6), and maximize over consumption of home and foreign goods by all cohorts to find the optimal solution. Note that the Lagrangian 
multipliers are the shadow prices of the home and foreign goods, and can thus be set as $\lambda_{h, t}=p_{h, t}$ and $\lambda_{f, t}=S_{t} p_{f, t}$. We are then left with the following results: ${ }^{7}$

$$
\begin{aligned}
c_{t}^{h, t} & =c_{t}^{h, t-1} \\
c_{t}^{f, t} & =c_{t}^{f, t-1} \\
c_{t}^{h, t} & =q_{t}^{\frac{1}{\gamma}} c_{t}^{f, t}
\end{aligned}
$$

Therefore, a social planner would optimally make home and foreign consumption equal across generations and the ratio home and foreign consumption perfectly correlated with the RER.

These optimality conditions can be thought of as two separate goals of the social planner. First, the equality conditions in (22) and (23) implies that the planner is concerned about inequality. Because the young and the old cohorts in each country have the same preferences, an imbalance between their consumptions reduces aggregate welfare. Second, equations (22-24) imply perfect risk sharing between all four cohorts. Thus, we can contemplate two potential roles for social security in our model: alleviate inequality within countries, and share risk between all agents. While inequality is fairly straightforward, we discuss risk sharing in detail below.

\subsection{Incomplete markets private solution}

We next compare the risk-sharing outcomes in the baseline specification (no pension system in either country) and in the benchmark versions with the $\mathrm{DB}$ and DC pension plans (at home only) to those of the social planner (SP) framework described above. ${ }^{8}$ To do so, we simulate each of the three specifications 1,000 times for 1,100 periods starting from a symmetric state of nature where wealth is evenly distributed between countries; we then discard the first

\footnotetext{
${ }^{7}$ See Appendix B for the derivations of the optimal conditions of the social planner.

${ }^{8}$ Throughout the paper, "baseline" will refer to symmetric parameterization of the model in the absence of a pension system, and "benchmark" will refer to the model calibration with the average level of taxes (either lump-sum or distortionary).
} 
100 periods to reduce the impact of the initial conditions on the final results. ${ }^{9}$ The data in the tables that follow are generated by computing the average of each relevant variable over the 1,000 remaining periods in each simulation, and then finding the mean of the averages across the simulations.

Since, in our model, the financial markets are incomplete, agents are not able to share risks fully either within or across countries. Moreover, the twocohort OLG structure means that the young and the old cannot use private markets to transfer risk across generations. Perfect pooling of risk would mean that all agents in the model can share their idiosyncratic risks with all other agents in the model: young workers born during a period of low wages should receive a transfer from the old cohort, and an adverse shock to dividends should trigger a transfer from the young cohort. However, the agents cannot form such contracts because these risks are realized as soon as the young cohort is born. Thus, it is too late for the two existing generations to enter into risksharing arrangements with each other, as it is impossible for the young to sign contracts with the (as yet unborn) generation that will follow them before the next period's risks are realized. As such, the young face a disproportionally high wage risk, and the retirees are overexposed to the dividend risk. The lack of diversification of human and financial capital risks reduces agents' welfare as long as wage and dividend streams are imperfectly correlated.

The lack of intergenerational risk-sharing exhibited in the OLG framework inhibits the ability of the RER to effectively transfer risk between the two countries. In infinitely-lived agents models, international risk-sharing is more the product of RER movements that result from productivity shocks than the outcome of a complex financial market (Cole and Obstfeld, 1991). Because intergenerational risk sharing is so low, the RER cannot accommodate risksharing between the four distinct cohorts. ${ }^{10}$ To some extent, changes in goods and asset prices in response to the shocks generate wealth transfers which affect

\footnotetext{
${ }^{9}$ Each specification is simulated using the same 1,000 shock histories (each 1,100 periods long). Thus, the differences in the outcomes are driven solely by the changes in the structure of the pension system.

${ }^{10}$ See Staveley-O'Carroll and Staveley-O'Carroll (2019) for a discussion of (the lack of) international risk sharing in two-country OLG models.
} 


\begin{tabular}{llrrr}
\hline \hline & SP & Baseline & $\mathbf{T}_{h}=\mathbf{0 . 2 8}$ & $\boldsymbol{\tau}_{h}=\mathbf{0 . 3 6}$ \\
\hline $\operatorname{Corr}\left(c_{t}^{h, t}, c_{t}^{h, t-1}\right)$ & 1.00 & 0.17 & 0.15 & 0.74 \\
$\operatorname{Corr}\left(c_{t}^{f, t}, c_{t}^{f, t-1}\right)$ & 1.00 & 0.17 & 0.25 & 0.18 \\
$\operatorname{Corr}\left(c_{t}^{h, t} / c_{t}^{f, t}, q^{\frac{1}{\gamma}}\right)$ & 1.00 & 0.44 & 0.35 & 0.46 \\
\hline \hline
\end{tabular}

Table 2: The degree of risk sharing under different assumptions about the home pension system. SP in the second column refers to the outcomes of the social planner problem. The baseline version of the model features to pension systems in either of the two economies. Setting $T_{h}>0\left(\tau_{h}>0\right)$ represents the DB (DC) structure of the home pension system.

risk sharing across the different groups of agents, but such effects are small in magnitude. Column 3 of Table 2 reveals that baseline simulation of the model has far less risk sharing than the optimal levels derived in the social planner's solution above (column 2). This outcome sets up the central question of the paper: to what extent can a state-run PAYG pension system rectify the key risk-sharing issue in the model - that the workers are not directly exposed to dividend shocks and the retirees are not directly exposed to wage shocks?

The optimal portfolios of the home agents are presented in Table 3. The baseline portfolio composition is driven by the particular parameterization of the utility function. Setting $\gamma=0.5$ (EIS) and $\alpha=60$ (risk aversion) means that the worker treats current and future consumptions as substitutes, and is very risk-averse within a given period. Since the households are not exposed to the wage risk in the second period of their lives, they invest in a fairly even split between home and foreign equity to pool the second-period dividend risk. They also go long in home and short in foreign bonds. The bond positions help to pool the nontradable first-period wage risk. Following a high realization of the home wage which raises home output, the RER depreciates, benefitting the foreign agent. Going long in home and short in foreign bonds amplifies this mechanism: the RER depreciation increases the cost of repaying foreign debt, further improving the extent of wage income risk sharing. ${ }^{11}$ The net

\footnotetext{
${ }^{11}$ An attentive and thorough reader may notice the difference in the optimal portfolios of the home agents presented here versus the ones described in Staveley-O'Carroll and Staveley-
} 


\begin{tabular}{lrrr}
\hline \hline & Baseline & $T_{h}=0.28$ & $\tau_{h}=0.36$ \\
\hline Home equity as a percent of home portfolio & 0.53 & 0.45 & 0.60 \\
Foreign equity as a percent of home portfolio & $(0.001)$ & $(0.005)$ & $(0.007)$ \\
& 0.47 & 1.66 & 0.15 \\
Home bonds as a percent of home portfolio & $0.001)$ & $(0.028)$ & $(0.001)$ \\
& 0.49 & 0.79 & 1.01 \\
Foreign bonds as a percent of home portfolio & $(0.003)$ & $(0.005)$ & $(0.005)$ \\
NFA as a percent of home GDP & $(0.003)$ & $(0.038)$ & $(0.012)$ \\
& 0.00 & -0.05 & -0.07 \\
& $(0.001)$ & $(0.001)$ & $(0.001)$ \\
\hline \hline
\end{tabular}

Table 3: Portfolio holdings of the home (young) worker. Equity holdings are measured as fractions of the total quantity of the corresponding equity asset. The baseline version of the model features to pension systems in either of the two economies. Setting $T_{h}>0\left(\tau_{h}>0\right)$ represents the DB (DC) structure of the home pension system.

foreign asset (NFA) position as a percent of home GDP is close to zero due to the baseline model symmetry.

The introduction of the pension system in the home country significantly affects the portfolio choices of the workers. In essence, the government introduces a new asset that cannot be traded in financial markets and which can be designed to alter the exposure of the retirees to labor income and of the workers to capital income. The DB and DC setups we explore next differ quite significantly in the extent to which they allow agents to pool the two sources of income both within borders and internationally.

The tax that accompanies the DB framework reduces the income of the young cohort as it transfers their purchasing power toward the next period, prompting them to increase their (net) borrowing to supplement this temporary loss. At the same time, since $T_{h}$ is not state-dependent, their second-

O'Carroll (2019). These differences are driven by the change in the preferences specification: EZ in the present paper and CRRA (log utility) in the latter publication. Since the households in this paper are less concerned with intertemporal consumption smoothing and more interested in lowering within-period consumption volatility, there is less intergenerational risk sharing and more international risk sharing here relative to the earlier paper. 
period wealth $\Omega_{t+1}^{h, t}$ is made safer for any given portfolio allocation $\left\{a_{h, t}^{h, t}, b_{h, t}^{h, t}, a_{f, t}^{h, t}, b_{f, t}^{h, t}\right\}$. This encourages the home workers to invest more heavily in equity. The preference for foreign over home equity is driven by the asymmetry in the global provision of state pensions: foreign workers must rely solely on their private investments to finance consumption in retirement and so choose safer bonds over riskier equity to reduce its expected volatility. ${ }^{12}$ The impact on risk-sharing (Table 2, column 4) is to allow consumption patterns to move more in sync within the foreign country as it unloads its risky assets onto the home country. This benefit comes at the cost of reduced risk-sharing intergenerationally in the home country, although this result should not be surprising: the lump-sum transfer from the young to the old not only fails to expose the retirees to the wage shock, but also reduces the income of the workers. Finally, international risk sharing (between the two groups of workers) falls as well, as the home worker now experiences a more volatile after-tax wage income.

The DC pension system, on the other hand, improves risk sharing in each of the four groups relative to the baseline level. It does so by pooling the risk of the wage shock between the old and young cohort in the home country, directly addressing one of the key reasons for low baseline risk sharing discussed above. Knowing that the pension payout is now stochastic, the home worker shifts away from risky equities to a (relatively more) safe portfolio that is long in debt assets (Table 3, column 4). This home-country benefit spills over to the foreign economy, since now all four agents are exposed (via the rebalancing of their equity and bond holdings) to fluctuations in the home wage. Our results suggest that the DC pension system can to some extend substitute for the incomplete private financial market: it offers a hedge against financial asset risk by providing a labor income-based benefit. This observation corresponds to the findings in Shiller (1999) and Krueger and Kubler (2006): in an environment where returns to capital and labor are imperfectly correlated, a PAYG social security system enables agents to pool the two sources of income and thereby helps to reduce the consumption variance of all generations. The

\footnotetext{
${ }^{12}$ The resulting "venture capitalist" pattern of asset holdings is further discussed in Staveley-O'Carroll and Staveley-O'Carroll (2017).
} 
benefits of the DC social security system may therefore be sensitive to the degree of correlation between the labor and dividend shocks in the model. We perform the corresponding robustness checks in Section 5.

Finally, it is worthwhile pointing out that this risk-pooling benefit of the DC system is independent of the number of cohorts in the model. In settings where multiple generations are alive concurrently, older workers who have already accumulated some financial wealth may be able to pool the dividend and wage risks using private markets. Even so, the pension system enables retirees, who by definition no longer participate in the labor markets, to share their portfolio risk with the labor income risk of the concurrent workers.

\section{Welfare Implications}

\subsection{Measures of Welfare}

Using the results of the baseline model simulations, we can compute the corresponding welfare levels $\left\{\hat{v}_{t}^{h, t}, \hat{v}_{t}^{f, t}, \hat{v}_{t}^{h, t-1}, \hat{v}_{t}^{f, t-1}\right\}$ of the agents using equations (5) and (6). In the exposition below, hats ("^ ") to refer to the baseline specification; we let $i=\{h, f\}$ denote the home and foreign agents, respectively, and $j=\{t, t-1\}$ refer to the young and the old cohorts, respectively.

Following the addition of either the DB or the DC program, we can measure the benefit to the four agents of living in a world with a social security system (in the home country) as follows. For each cohort, we calculate a scalar $C V_{t}^{i, j}$ that equates the baseline lifetime utility level $\hat{v}_{t}^{i, j}$ with that obtained under the particular pension setup:

$$
\begin{aligned}
\left\{\left[c_{t}^{i, t}+C V_{t}^{i, t}\right]^{1-\gamma}+\beta E\left[\left(\hat{v}_{t+1}^{i, t}\right)^{1-\alpha}\right]^{\frac{1-\gamma}{1-\alpha}}\right\}^{\frac{1}{1-\gamma}} & =\hat{v}_{t}^{i, t} \\
c_{t}^{i, t-1}+C V_{t}^{i, t-1} & =\hat{v}_{t}^{i, t-1}
\end{aligned}
$$

The variables $C V_{t}^{i, j}$ represent the compensating variations - additional amount of current consumption - required to make the consumer indifferent to having 
the social security system in place. ${ }^{13} \mathrm{~A}$ positive (negative) value of $C V_{t}^{i, j}$ means that the addition of a pension system makes the consumer worse off (better off). (Recall that we are comparing two long-run stochastic equilibria that exclude any transitional period considerations.) Working through the definitions of $C V_{t}^{i, j}$ and $\hat{v}_{t}^{i, j}$ results in the following equality:

$$
C V_{t}^{i, j}=c_{t}^{i, j}-\hat{c}_{t}^{i, j}
$$

Since the compensating variations are measured in units of home and foreign consumptions bundles, they can be easily aggregated:

$$
\begin{aligned}
C V_{t}^{i} & \equiv C V_{t}^{i, t}+C V_{t}^{i, t-1} \\
C V_{t} & \equiv C V_{t}^{h}+q_{t} C V_{t}^{f}
\end{aligned}
$$

allowing us to study the distribution of aggregate welfare across generations and countries. We scale these values by the appropriate consumption levels in the discussion below:

$$
\begin{aligned}
c v_{t}^{i, j} & \equiv \frac{C V_{t}^{i, j}}{c_{t}^{i, j}} \\
c v_{t}^{i} & \equiv \frac{C V_{t}^{i}}{c_{t}^{i, t}+c_{t}^{i, t-1}} \\
c v_{t} & \equiv \frac{C V_{t}}{c_{t}^{h, t}+c_{t}^{h, t-1}+q_{t}\left(c_{t}^{f, t}+c_{t}^{f, t-1}\right)} .
\end{aligned}
$$

\subsection{Defined Benefit}

The calculations, shown in columns 2-4 of Table 4 , reveal that a DB social security system in the home country increases the welfare of the old cohorts in the model at the expense of the working cohorts. This outcome is broadly con-

\footnotetext{
${ }^{13}$ Note that the utility function of the young worker assumes that she will also receive compensation in the future period. This is necessary to allow for the aggregation of compensating variations in a specific period without double-counting the benefits of the social security payments in the form of current payments to the current retired cohort and expected future benefits for the current young cohort.
} 
sistent with the findings in Shiller (1999), who illustrates the underlying cost of all PAYG social security systems. The young workers are taxed to pay for the old cohort's retirement benefits and so lose out on returns that could have accrued on these funds. ${ }^{14}$ When a PAYG system is first introduced, the current retirees receive a payout from a system to which they never contributed. This financial gap persists over time as the consecutive generations of workers lose the potential earnings on pension tax payments that could otherwise have been saved. ${ }^{15}$ To some extent, the home worker compensates for this loss by investing more heavily in (foreign) equity to earn the above-average rate of return; nonetheless, the net benefit to the home young of the DB social security system is negative. (We should note, however, that our model abstracts from many real-world features, such as savings myopia or the uncertainty of life duration in retirement, adding which could lead to a much higher net benefit of a government-run pension system from the worker perspective.)

Once aggregated over generations, our results suggest that the costs to the home country of implementing a DB pension system are accompanied by gains in the foreign country (notice that $\overline{c v}_{t}^{h}>0$ and $\overline{c v}_{t}^{f}<0$ ). The source of these gains is twofold. First, the social security system that impoverishes the young workers at home causes them to become net debtors (recall the negative NFA position reported in Table 3). Correspondingly, the young foreign cohorts necessarily become net lenders, providing them with higher lifetime consumption (although, as Table 4 indicates, this benefit applies to the second period of

\footnotetext{
${ }^{14}$ Since in our model there is no population growth, the implied rate of return on social security contributions is zero.

${ }^{15}$ It is fairly straightforward to calculate the corresponding burden on the workers. The present discounted value of the (infinite sum of the) foregone returns $r$ on tax payments $T_{h}$ is simply $r T_{h}=T_{h}\left(\frac{1}{\beta}-1\right)$. Given the 25-year discount factor $\beta=0.375$ and the three values of the tax we consider, $T_{h}=\{0.1,0.28,0.46\}$, we can calculate that workers lose a cumulative income of $\{0.167,0.468,0.768\}$, depending on the level of the lump-sum tax. Expressed relative to the average real output (1.425), these foregone risk-free earnings are equal to $\{11.72 \%, 32.83 \%, 53.93 \%\}$ of home GDP. Feldstein and Leibman (2002) report similarly-sized losses using a stylized model of social security: even if only one seventh of the pension taxes were diverted to savings, the present value of consumption losses due to social security would be more than double the value of the gain to the first generation of retirees.
} 


\begin{tabular}{lrrrrrr}
\hline \hline & $\mathbf{T}_{h}=\mathbf{0 . 1}$ & $\mathbf{T}_{h}=\mathbf{0 . 2 8}$ & $\mathbf{T}_{h}=\mathbf{0 . 4 6}$ & $\boldsymbol{\tau}_{h}=\mathbf{0 . 1 2 4}$ & $\boldsymbol{\tau}_{h}=\mathbf{0 . 3 6}$ & $\boldsymbol{\tau}_{h}=\mathbf{0 . 6}$ \\
\hline$\overline{c v}_{t}^{h, t}$ & 8.48 & 30.80 & 74.16 & 12.14 & 43.39 & 102.32 \\
$\overline{c v_{t}^{f, t}}$ & 0.37 & 1.10 & 1.78 & -0.82 & -0.85 & -0.58 \\
$\overline{c v_{t}^{h, t-1}}$ & -0.96 & -4.28 & -7.63 & 11.35 & 11.87 & 7.16 \\
$\overline{c v_{t}^{f, t-1}}$ & -6.96 & -16.89 & -25.58 & -17.65 & -29.97 & -37.49 \\
$\overline{c v_{t}^{h}}$ & 3.73 & 10.83 & 20.35 & 12.07 & 27.47 & 43.49 \\
$\overline{c v}_{t}^{f}$ & -3.06 & -7.88 & -12.74 & -9.39 & -16.69 & -21.67 \\
$\overline{c v_{t}}$ & -0.02 & -0.12 & -0.33 & -0.15 & -0.55 & -1.03 \\
\hline \hline
\end{tabular}

Table 4: Welfare cost, in percent of current consumption, of social security system in the home country,

Notes. (a): All statistics are significant at the 1 percent level.

life). Second, the safety net provided by the DB system allows the foreign workers to transfer some of their risk to the home investors (Table 3, column 2 ). Thus, the national pension system provision in the home country allows its consumers, through the financial market linkages, to share the reduction in their lifetime income risk internationally. However, since the gains to the foreign young are expected rather than realized, the biggest benefit of the pension system accrues to the foreign retirees, who get to enjoy the lower-risk payout of their higher retirement wealth. As discussed in the previous section, this creates greater risk sharing within the foreign country (Table 2, column $3)$.

Finally, shown in the last row of Table 4, the global welfare improves slightly following the addition of a DB pension system in one of the countries. ${ }^{16}$ The DB pension in our model is structured as a simple lump sum transfer and, as such, does nothing to improve the overall risk sharing within the model. Where, then, does this small yet statistically significant benefit come from? The answer lies in the redistributive properties of the social security system. Recall from equations (22) and (23) that the social planner would optimally set consumptions within each country equal. However, as illustrated in the

\footnotetext{
${ }^{16}$ Since the home country maintains a negative NFA position in both DB and DC setups, the average RER is greater than one. Consequently, the seemingly higher percentage losses at home are more than offset by the corresponding gains abroad.
} 


\begin{tabular}{llll}
\hline \hline & Baseline & $\mathbf{T}_{h}=\mathbf{0 . 2 8}$ & $\boldsymbol{\tau}_{h}=\mathbf{0 . 3 6}$ \\
\hline$c_{t}^{h, t}$ & $0.77(0.007)$ & $0.61(0.007)$ & $0.54(0.004)$ \\
$c_{t}^{h, t-1}$ & $0.64(0.005)$ & $0.68(0.007)$ & $0.58(0.004)$ \\
$c_{t}^{f, t}$ & $0.77(0.007)$ & $0.77(0.007)$ & $0.78(0.007)$ \\
$c_{t}^{f, t-1}$ & $0.64(0.005)$ & $0.77(0.006)$ & $0.92(0.007)$ \\
\hline \hline
\end{tabular}

Table 5: Levels of current consumption for the baseline and benchmark DB and DC systems.

second column of Table 5, the young cohorts do not save enough to smooth their consumption over the two periods of life. ${ }^{17}$ This suboptimal behavior is partially mitigated by the DB pension system (column 3 of Table 5), which - by taxing the young and transferring the proceeds to the retirees - substantially reduces the inter-cohort consumption gap in each country.

\subsection{Defined Contribution}

In reality, most social security systems are structured as hybrids of pure DB and DC frameworks, since the government can bridge the gap between the volatile income tax revenue and the guaranteed benefit payouts by borrowing or saving. The computational constraints imposed by our model, however, require the government to run a balanced budget every period, so that pension contributions match payouts at all times. However, to better understand the findings reported above, we replace the DB pension with a DC system by setting $T_{h}=0$ and $\tau_{h}>0$.

The results, shown in columns $5-7$ of Table 4 , reveal that a DC social security system in the home country increases the welfare of both foreign cohorts in the model at the expense of the home cohorts. The home worker's pension payment is now procyclical, and so the young cohort that enters the workforce during the period of low wages is relatively more shielded from the shock than in the DB setup. On the other hand, in addition to suffering the

\footnotetext{
${ }^{17}$ This result may be partially driven by the assumed value of EIS: setting $\gamma=0.5$ implies that current and future consumptions are viewed by households as imperfect substitutes. We test the robustness of our results to changes in this parameter value in Section 5.
} 
costs of the foregone investment earnings while young, the home cohorts also receive relatively little safety from their pension payments, which now fluctuate together with wages. Consequently, the home consumer no longer takes on as much portfolio risk when young and so does not enjoy higher consumption during her retirement. Abroad, in addition to earning returns from being net lenders, foreign cohorts also hold more of the home country's risk (Table 3, column 3). This portfolio shift from the DB to the DC system amplifies both the gains to the foreign cohorts and the losses to the home cohorts.

The welfare gains to the foreign country outweigh the losses to the home economy even more so than under the DB setup, ranging from $0.15 \%$ to $1.03 \%$ of global output. This is less the result of consumption redistribution (which is not as effective as in the DB case; see column 4 of Table 5) and more the outcome of the improved risk sharing (Table 2, column 5).

\section{Robustness checks}

The above welfare results are broadly robust to a series of parameter changes. Before diving into the details, we would like to highlight the universally unchanged conclusion of our paper: the introduction of a pension system in one economy produces global welfare gains.

\subsection{Defined benefit}

Table 6 describes the results of parameter value changes on the welfare gains/losses in the benchmark DB system. In all specifications, the loss in the home country is more than offset by the spillover gains in the foreign country.

The literature has not yet reached consensus on the appropriate value of the EZ preference parameters. Since the assumed form of the utility function is of key importance to the resulting welfare calculations, we repeat our simulations for several additional combinations of the two parameters: $(\alpha, \gamma)=\{(2,0.5),(60,2),(1,1)\}$, the latter corresponding to log utility of consumption. Lowering the degree of risk aversion (column 3 of Table 6) changes 
the magnitudes of the resulting welfare gains and losses, but produces only one change in the sign: the home retirees now experience welfare losses following the addition of the DB pension system. Since all agents in the model are made less risk averse, the benefit to the older cohort of having a guaranteed secondperiod income is lowered. The cost of foregone income due to the tax burden more than offsets the now smaller gains from having a retirement safety net. Notably, lower risk aversion leads to larger global welfare gains stemming from lower inequality between the cohorts.

Setting $\gamma=2$ makes current and future consumptions complementary and therefore increases households' desire to smooth consumption intertemporally. Consequently, international consumption inequality is likely to become more persistent over time. As a result, the costs of the social security system are now completely contained within the home country whereas all of its benefits are transferred abroad. Assuming complementarity between first and second period consumption also increases the volatility of prices (and, in particular, of the RER), since for any given endowment shock a larger relative price movement is required to shift consumer spending to the more plentiful good. Coupled with the more persistent consumption inequality, this RER dynamic amplifies the foreign welfare gains relative to the losses suffered in the home country. Nonetheless, even though driven by different factors, the magnitude of the country-specific welfare outcomes is almost unchanged relative to the benchmark.

The third sensitivity exercise $(\alpha=\gamma=1)$ collapses EZ preferences to log utility, a specification widely used in international macroeconomic literature. The result of this parameter change essentially combines the above two robustness checks: the welfare values are fairly similar to the $\alpha=2$ specification, while their signs follow the pattern of the $\gamma=2$ check. As before, the main conclusion remains the same: the cost of the pension system is borne by the home country, while benefits are enjoyed abroad. 


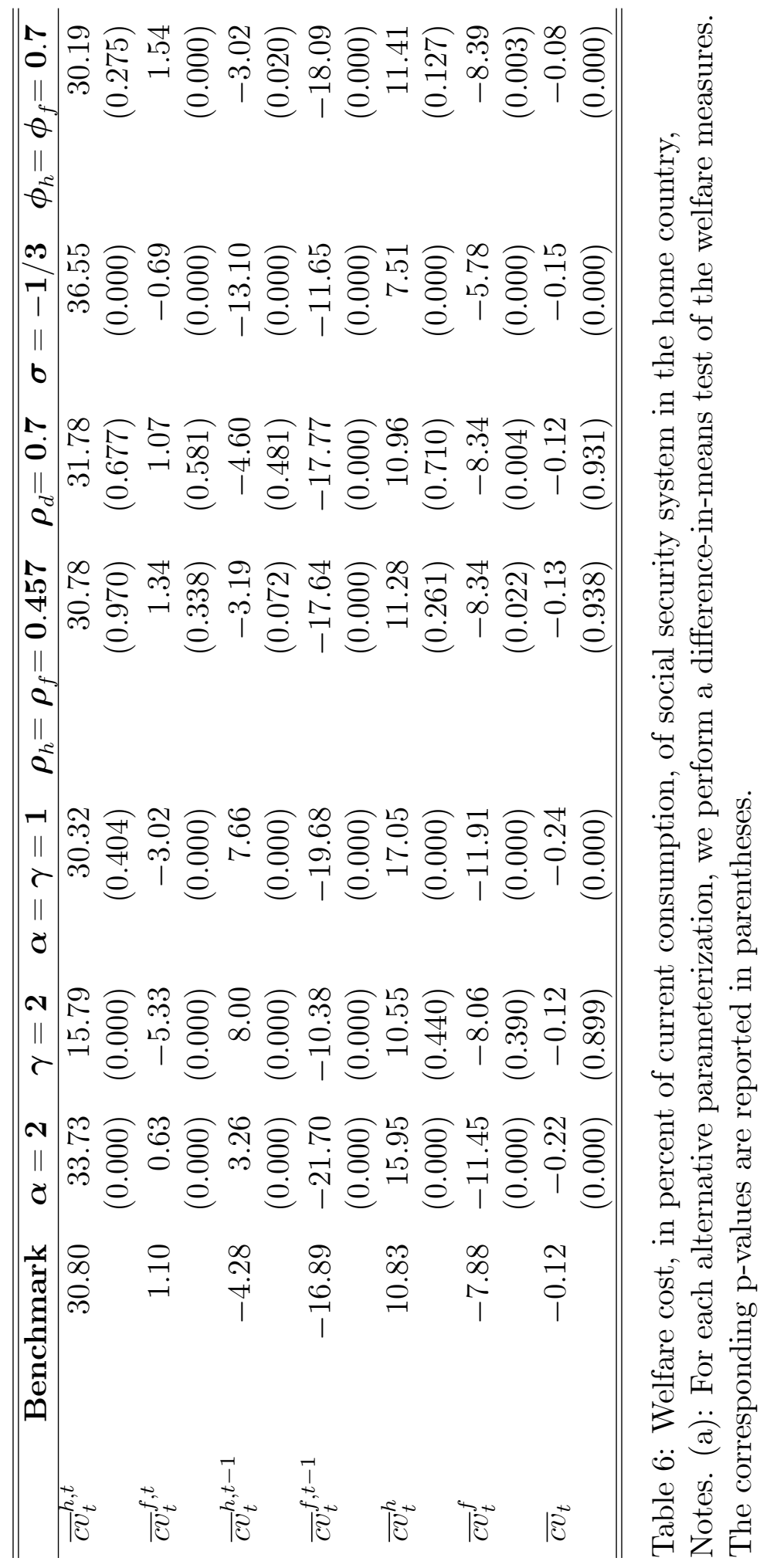




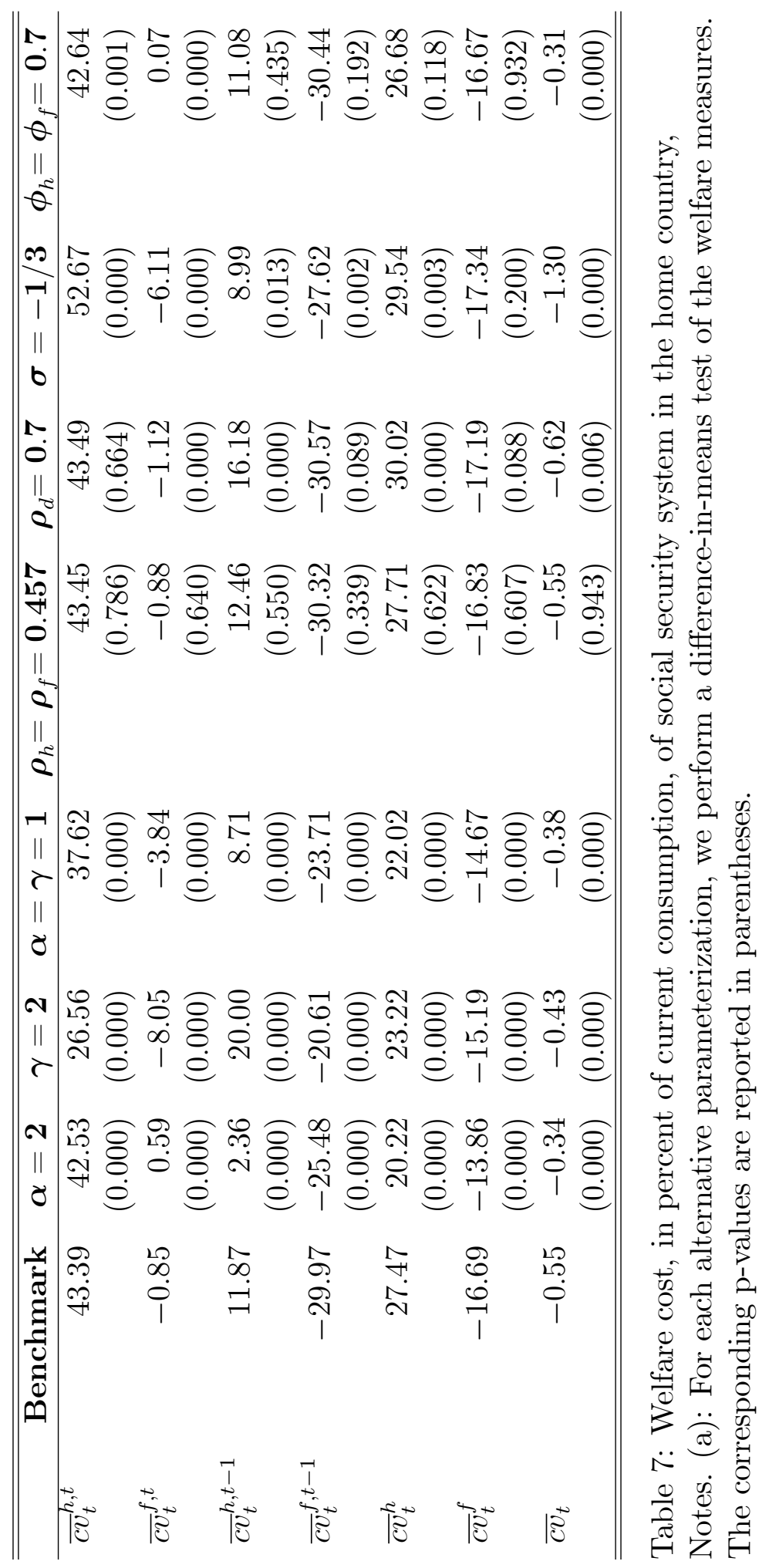


Trade elasticity $\frac{1}{1-\sigma}$ can significantly affect the extent of cross-border risk sharing via the RER. The parameter estimates in the literature, however, range from $\sigma=-3.55$ (complements) to 0.83 (substitutes), as reported in Bodenstein (2010). As home and foreign goods are made more complementary (setting $\sigma=-1 / 3$ ), RER volatility increases: an ever larger RER fluctuation is necessary to shift demand between the two goods. This substantially increases the social security gains to the older home cohort, since wealth cannot be transferred abroad as easily.

The last three tests - assuming positive correlation between dividends and wages within each country, between home and foreign dividend processes, or changing the extent of home bias in consumption-produce only minor changes in the welfare results.

\subsection{Defined contribution}

Table 7 describes the outcomes of the same series of robustness checks relative to the benchmark DC system.

As described in Section 4.3, the welfare results in the DC framework are driven more by improved risk sharing than income redistribution. Unsurprisingly, therefore, lowering risk aversion from 60 to 2 lowers the absolute value of all compensating variations since agents are now less sensitive to the risks inherent in the model. More importantly, the benchmark gains to the foreign workers from unloading their country-specific risks onto the home young are now turned into losses. On the other hand, changing the EIS parameter from 0.5 to 2 has less of an effect on the overall results than under the DB specification, since EIS affects the degree of consumption inequality which is less important to welfare in the DC framework. The gains in the foreign country and the losses in the home country are more evenly spread out, which is expected when households improve consumption smoothing (Table 7, column 3). The next column shows that the benchmark results are fairly robust to the log utility specification.

Assuming that imports and exports are complements $(\sigma=-1 / 3)$ rather 
than substitutes $(\sigma=1 / 3)$ reduces international risk-sharing. Consequently, the aggregate welfare gains from improved risk sharing due to a DC pension system increase substantially from $0.55 \%$ to $1.30 \%$ of global output.

As in the previous subsection, adding positive within-country wage-dividend correlations or cross-country dividend correlation, or lowering the degree of home bias in consumption produce only minor changes in the welfare results relative the benchmark calibration.

\section{Conclusions}

This paper analyzes the (possibly unforeseen and perhaps unintended) international risk-sharing and welfare consequences of national pension systems in a setting where risks cannot be fully traded between generations in private financial markets. We show that these consequences depend critically on the particular structure - defined benefit or defined contribution - of the system. Our main findings are twofold.

First, asymmetries in the provision of national retirement systems produce international risk-sharing spillovers via the financial market linkages. Under the DB setup, home workers can share the risk reduction in their lifetime income, induced by the pension system, with the foreign consumers: the latter can offload some of their risky assets in exchange for relatively safer bonds. Thus, the existence of the DB PAYG system in one country can indirectly improve the extent of intergenerational risk sharing in the other. As opposed to the DB structure, the DC system leads to much higher risk sharing within generations and internationally. Home young and old are now sharing wage risk more equally, and this risk can also be hedged internationally via appropriately chosen portfolios of the home and foreign workers.

Second, the addition of the pension system in the home country is welfarereducing for the home young (and, in the DC case, for the home retirees as well) but leads to welfare gains abroad. The latter stem from the willingness of home investors to take on additional risk associated with foreign equity (DB) and/or from the foreign country becoming a net international lender as 
home workers seek to supplement the loss of their current income to the social security tax with foreign borrowing. Once again, we should note that the simplifying assumptions of the model, necessary for computational considerations, require that our welfare results be interpreted as supplementary to many other welfare gains and losses associated with social security and documented elsewhere in the literature.

An important question for future research is how the two-cohort results generalize to overlapping-generations models with multiple cohorts alive concurrently. In such settings, older workers with access to both wage and dividend income may be able to pool the corresponding risks with the younger cohorts, thus mitigating the welfare effects reported in this paper. Another (complementary) way to allow for intergenerational risk sharing that extends beyond the two generations alive at a particular point in time would be to introduce government debt or a pension fund to our framework. Doing so would allow for wealth transfers and smoothing of shocks across multiple periods, thus further improving the extent of risk pooling in the model. 


\section{A References}

\section{References}

[1] Aubuchon, C., Conesa, J., Garriga, C., 2011. A primer on social security systems and reforms. Federal Reserve Bank of St. Louis Review, 93, 19-35.

[2] Beetsma, R., Bovenberg, A.L., Romp, W., 2011. Funded pensions and intergenerational and international risk sharing in general equilibrium. Journal of International Money and Finance, 30, 1516-1534.

[3] van Binsbergen, J., Fernández-Villaverde, J., Koijen, R., Rubio-Ramírez, J., 2012. The term structure of interest rates in a DSGE model with recursive preferences. Journal of Monetary Economics, 59, 634-648.

[4] Bodenstein, M. , 2010. Trade elasticity of substitution and equilibrium dynamics. Journal of Economic Theory, 145, 1033-1059.

[5] Bohn, H., 2009. Intergenerational risk sharing and fiscal policy. Journal of Monetary Economics, 56, 805-816.

[6] Bruce, N., Turnovsky, S., 2013. Social security, growth, and welfare in overlapping generations economies with or without annuities. Journal of Public Economics, 101, 12-24.

[7] Chari, V.V., Kehoe, P., McGrattan, E., 2002. Can sticky price models generate volatile and persistent real exchange rates? Review of Economic Studies, 69, 533-563.

[8] Cole, H., Obstfeld, M., 1991. Commodity trade and international risk sharing: how much do financial markets matter? Journal of Monetary Economics, 28, 3-24.

[9] Diamond, P., 2004. Social Security. The American Economic Review, 94, 1-24. 
[10] Diamond, P., 1965. National debt in a neoclassical growth model. The American Economic Review, 59, 1127-1155.

[11] Dicks-Mireaux, L., King, M.A., 1983. Portfolio composition and pension wealth: an econometric study. In Z. Bodie and J. Shoven (Eds.), Financial aspects of the United States pension system (pp. 399-440).

[12] Feldstein, M., Liebman, J., 2002. Social security. In: A. J. Auerbach \& M. Feldstein (ed.), Handbook of Public Economics, edition 1, volume 4, chapter 32, 2245-2324.

[13] Fischer, S., 1983. Welfare aspects of government issue of indexed bonds. In R. Dornbusch and M.H. Simonsen (Eds.), Inflation, Debt, and Indexation (pp. 247-266). Cambridge: M.I.T. Press.

[14] Harenberg, D., Ludwig, A., 2015. Social security in an analytically tractable overlapping generations model with aggregate and idiosyncratic risks. International Tax and Public Finance, 22, 579-603.

[15] Hubbard, R.G., 1985. Personal taxation, pension wealth, and portfolio composition. The Review of Economics and Statistics, 67, 53-60.

[16] Hubbard, R.G., Skinner, J., Zeldes, S., 1995. Precautionary saving and social insurance. Journal of Political Economy, 103, 360-399.

[17] Hubener, A., Maurer, R., Mitchell, O., 2016. How family status and Social Security claiming options shape optimal life cycle portfolios. Review of Financial Studies, 29, 937-978.

[18] Judd, K. , Kubler, F. , Schmedders, K. , 2003. Asset trading volume with dynamically complete markets and heterogeneous agents. The Journal of Finance, 58, 2203-2217.

[19] Krueger, D., Kubler, F., 2006. Pareto-improving social security reform when financial markets are incomplete!? The American Economic Review, $96,737-755$. 
[20] Ligon, J., 1995. The impact of retirement wealth upon portfolio composition of individuals. Journal of Economics and Business, 47, 303-316.

[21] Samuelson, P., 1975. Optimum social security in a life-cycle growth model. International Economic Review, 16, 539-544.

[22] Sánchez-Marcos, V., Sánchez-Martín, A., 2006. Can social security be welfare improving when there is demographic uncertainty? Journal of Economic Dynamics and Control, 30, 1615-1646.

[23] Shiller, R., 1999. Social security and institutions for intergenerational, intragenerational, and international risk-sharing. Camegie-Rochester Conference Series on Public Policy, 50, 165-204.

[24] Staveley-O'Carroll, J., Staveley-O'Carroll, O., 2019. International risk sharing in overlapping generations models. Economics Letters, 174, 157160 .

[25] Staveley-O'Carroll, J., Staveley-O'Carroll, O., 2017. Impact of pension system structure on international financial capital allocation. European Economic Review, 95, 1-22.

[26] Stepanchuk, S., Tsyrennikov, V., 2015. Portfolio and welfare consequences of debt market dominance. Journal of Monetary Economics, 74, 89-101.

[27] Storesletten, K., Telmer, C., Yaron, A., 1999. The risk-sharing implications of alternative social security arrangements. Carnegie-Rochester Conference Series on Public Policy, 50, 213-259. 